\title{
Acessibilidade à informação: proposta de uma disciplina para cursos de graduação na área de biblioteconomia
}

\author{
Sonia Nascimento de Paula \\ Mestranda em ciência da informação da Pontifícia Universidade \\ Católica de Campinas, SP, Brasil \\ E-mail:snpaula@hotmail.com
}

\author{
José Oscar Fontanini de Carvalho \\ Doutorado em engenharia elétrica pela Universidade Estadual de \\ Campinas (Unicamp), Campinas, SP, Brasil. Professor do Centro \\ de Ciências Exatas, Ambientais e de Tecnologia da Pontifícia \\ Universidade Católica de Campinas - PUC Campinas, Campinas, \\ SP, Brasil \\ E-mail: oscar@oscar.pro.br
}

\section{Resumo}

A pesquisa tem como objetivo propor uma disciplina que ajude na formação do bibliotecário no atendimento da pessoa com deficiência em bibliotecas universitárias. Temas abordados: o acesso à informação; aspectos históricos da acessibilidade; legislação e a pessoa com deficiência; atribuições dos bibliotecários nos serviços prestados à comunidade universitária. Foram analisados dois programas de acessibilidade em bibliotecas universitárias brasileiras: Programa de Acessibilidade da PUC-Campinas (ProAces); Laboratório de Acessibilidade da Unicamp (LAB), por serem referência na literatura da área, servindo de base para a proposta da disciplina. A análise revelou barreiras e soluções encontradas para facilitar o acesso à informação do aluno com deficiência. A pesquisa foi do tipo exploratória e descritiva, valendo-se da pesquisa bibliográfica e observações em bibliotecas acessíveis.

\section{Palavras-chave}

Acessibilidade. Inclusão digital. Alunos com deficiência. Currículo de cursos de graduação em biblioteconomia.

\author{
Information accessibility: proposal in a \\ discipline for librarian undergraduate \\ courses
}

\begin{abstract}
The objective of this article is to propose accessibility to information as a discipline for helping librarians to render services to disabled people in university libraries. The main topics are access to information; historical aspects of accessibility; legislation on disabled people; and attributions of librarians rendering services to the university community. Two programs about accessibility to Brazilian universities were analyzed: Program of Accessibility of PUC-Campinas (ProAces) and Laboratory of Accessbility of Unicamp ( $L A B)$. These programs are a reference in literature of this area and are used as a basis for proposing this discipline. Barriers were found and solutions presented for making the access to information easier for disabled people. An exploratory and descriptive analysis based mainly on bibliographic research and visits to accessible libraries.
\end{abstract}

\section{Keywords}

Accessibility. Digital inclusion. Students with disabilities. Curriculum of graduation courses in library science. 


\section{INTRODUÇÃO}

A portaria no 3.284 , do Ministério de Educação e do Desporto (MEC), desde 2003 garante à pessoa com deficiência o direito de acessibilidade à educação em todos os níveis, em instituições públicas ou privadas, sendo assegurado ao aluno o atendimento de suas necessidades até a conclusão do curso. Contudo, dados do censo universitário 2003, realizado pelo Instituto Nacional de Estudos e Pesquisas Educacionais Anísio Teixeira (Inep), demonstram a baixa inserção dessa faixa de população nos ambientes acadêmicos.

Para o MEC, o ensino superior é um direito de caráter público, capaz de garantir a permanência da população em situação de desvantagem nas instituições públicas de ensino superior, visando a diminuir as desigualdades e garantir um futuro melhor, mediante uma educação de qualidade, do ensino infantil ao superior. A Lei de Diretrizes Bases (LDB, 1997) assegura esse direito às pessoas com deficiência, exigindo, para isso, adequação de currículos, métodos, técnicas e recursos para atender às suas especificidades.

Apesar disso, de acordo com Pupo e Vicentini (1998, p.3), muitos alunos com deficiência "iniciam uma atividade de pesquisa na universidade e são barrados pela inexistência de uma infra-estrutura adequada." Para facilitar sua permanência, é preciso eliminar barreiras de acesso ao câmpus universitário e à biblioteca.

Esta pesquisa se justifica pela relevância do tema, uma vez que na área da ciência da informação são apresentados diversos trabalhos, artigos e estudos tratando da acessibilidade de pessoas com deficiência a bibliotecas universitárias, mostrando a preocupação dos profissionais com o tema. Diante dos motivos apresentados, o presente trabalho se justifica pela constatação, na bibliografia pesquisada e in loco (PUC-Campinas e Unicamp), da existência, em bibliotecas universitárias, de barreiras que dificultam o atendimento de pessoas com deficiência.

Ci. Inf., Brasília, DF, v. 38, n. 3, p.64-79, set./dez., 2009
No aspecto social, a pesquisa proposta se justifica pela tentativa de apoiar o preparo do bibliotecário para prestar atendimento de qualidade às pessoas com deficiência que fazem uso de bibliotecas universitárias, sem receios ou preconceitos.

No contexto desta pesquisa, será adotada a expressão biblioteca universitária e não bibliotecas de instituições de ensino superior (IES), por ser aquela maneira utilizada na literatura da área, abrangendo as bibliotecas de IES, universidades e/ ou faculdades.

Como procedimento metodológico, além da técnica de observação direta intensiva, este trabalho envolveu:

a) pesquisa bibliográfica;

b) observação e análise de dois exemplos de bibliotecas universitárias acessíveis, a saber, a biblioteca da Unicamp e a biblioteca da PUCCampinas, escolhidas por serem identificadas como pioneiras em projetos de acessibilidade em bibliotecas universitárias e consideradas referência na literatura da área da ciência da informação. Outro motivo da escolha é a localização, ambas em Campinas, que facilitou o acesso para o teste de aplicabilidade.

\section{PESSOAS COM DEFICIÊNCIA E ACESSIBILIDADE}

Antes de caracterizar as pessoas com deficiência e a acessibilidade, é oportuno traçar um panorama histórico do problema.

\section{Histórico}

A relação entre a sociedade e o indivíduo com deficiência começou a mudar após as duas guerras mundiais, quando pessoas mutiladas voltavam para casa, passando a haver melhor aceitação da sociedade a esse segmento social.

Nos anos 90, após a Declaração de Salamanca, em 1994, a sociedade brasileira passou a debater questões essenciais à vida em sociedade, ocorrendo 
uma movimentação de educadores em busca de qualificação para as novas demandas. Assim, número crescente de pais de alunos buscou assegurar o direito de seus filhos, independentemente da natureza das necessidades especiais, matricularemse na escola das suas comunidades e frequentarem as atividades das classes comuns, juntamente com seus pares não deficientes. (OMOTE, 2004, p.2-3)

Portanto, a diferença passa a ser valorizada e a inclusão das pessoas com deficiência em escolas regulares é enfatizada.

\section{Legislação internacional}

Alguns documentos que tratam da questão da deficiência em plano mundial (PUPO, 2006) são relacionados a seguir:

- Declaração de Direitos Humanos - ONU em 1948.

- Carta para o Terceiro Milênio - Reabilitação Internacional, 09/09/1999: medidas para proteger os direitos das pessoas com deficiência mediante o apoio ao pleno empoderamento (empowerment) e inclusão em todos os aspectos da vida.

- Declaração de Madri, em 21/05/2002: parâmetro conceitual para a construção de uma sociedade inclusiva, focalizando os direitos das pessoas com deficiência, as medidas legais, mudança de atitude, a vida independente, entre outros.

- Declaração de Quito, 11/04/2003: governos da América Latina defendem uma Convenção Internacional para Proteção e Promoção dos Direitos e Dignidade das Pessoas com Deficiência - ONU.

\section{Legislação brasileira}

Em nível nacional, alguns documentos legais a respeito do tema incluem:

- Constituição Federal de 1988: direito das pessoas com necessidades educacionais especiais (NEE) à educação na rede regular de ensino.

- Lei n. 10.098, 19/12/2000 - Estabelece normas gerais e critérios básicos para a promoção da acessibilidade das pessoas portadoras de deficiência ou com mobilidade reduzida mediante a supressão de barreiras e de obstáculos nas vias e espaços públicos, no mobiliário urbano, na construção e reforma de edifícios e nos meios de transporte e de comunicação.

- Parecer n. 17/2001, 03/07/2001 - aprovado pelo Conselho Nacional de Educação: Relatório da Câmara de Educação Básica sobre Diretrizes Nacionais para a Educação Especial na Educação Básica.

Para melhor entendimento de termos utilizados na legislação e existentes na pesquisa, faz-se necessário apresentar alguns conceitos a seguir: pessoa com deficiência, acessibilidade, inclusão social, conceitos inclusivistas e inclusão digital.

\section{Conceitos}

Pereira (2004) comenta que ainda existem dúvidas quanto ao termo correto a ser usado com relação à pessoa com deficiência. A legislação brasileira adota o termo "portador de deficiência", mas Werneck (2003, apud Pereira, 2004) defende a ideia de que "pessoas não carregam suas deficiências nas costas necessariamente como um fardo e, de vez em quando, descansam delas para conseguir um trabalho mais bem remunerado". Portanto, o mais coerente seria adotar a expressão "pessoa com deficiência." Entende-se que pessoa com deficiência não é sinônimo de pessoa com necessidades especiais. Considerando que pessoa com necessidades especiais pode ser o resultado de condições atípicas, tais como deficiência mental, física, auditiva, visual ou múltipla; autismo; dificuldade de aprendizagem; insuficiências orgânicas; superdotados; problemas de conduta; distúrbio de déficit de atenção com hiperatividade, distúrbio obsessivo compulsivo, síndrome de Tourette; distúrbios emocionais e transtornos mentais.

Pessoas com deficiência

Neste trabalho, optou-se por utilizar a expressão "pessoa com deficiência”, por ser esta expressão apresentada na literatura de educação especial por 
estudiosos sobre o tema, uma vez que esta pesquisa se concentra no acesso à informação da pessoa com deficiência.

Segundo o Decreto n.5.296, de 2/12/2004, o termo deficiência significa uma restrição física, mental ou sensorial de natureza permanente ou transitória que limita a capacidade de exercer uma ou mais atividades essenciais da vida diária:

- deficiência física - alteração completa ou parcial de um ou mais segmentos do corpo humano, acarretando o comprometimento da função física;

- deficiência auditiva - perda parcial ou total das possibilidades auditivas sonoras, variando em graus e níveis;

- deficiência visual - acuidade visual igual ou menor que $20 / 200$, campo visual inferior a 20 ;

- deficiência mental - funcionamento intelectual inferior à média com manifestação antes dos 18 anos e limitações associadas a duas ou mais áreas de habilidades adaptativas, tais como comunicação; cuidado pessoal; habilidades sociais e outras;

- deficiência múltipla - é a associação, no mesmo indivíduo, de duas ou mais deficiências primárias (mental/visual/auditiva/física) com comprometimento que acarreta consequências no seu desenvolvimento global e na sua capacidade adaptativa.

Acessibilidade

Prover acessibilidade é remover barreiras que impeçam as pessoas com deficiência de participarem de atividades do cotidiano, incluindo o uso de serviços, produtos e informação. Entende-se que acessibilidade se refere à capacidade de ambientes e produtos serem usados por todas as pessoas (DIAS, s.d.).

A acessibilidade à informação digital só é possível quando são eliminadas barreiras de comunicação, quando os desenvolvedores de tecnologia digital se preocupam em facilitar o seu acesso a todas as pessoas, independentemente de sua situação social, econômica, intelectual e cultural, minimizando sua dificuldade em operar determinados tipos de máquinas digitais, criando interfaces - superfícies de contato que refletem as propriedades físicas das partes que interagem, as funções a serem executadas e o balanço entre poder e controle (Rocha, Baranauskas, 2003) - bem elaboradas, levando-se em conta as dificuldades encontradas pelo usuário, fazendo uso da interação humano-computador. Somente assim, as pessoas vão deixar de fazer parte dos excluídos da sociedade da informação (CARVALHO, 2003).

Portanto, a acessibilidade está relacionada com inclusão social e inclusão digital, como será apresentado a seguir.

\section{Inclusão social}

A inclusão social é o processo pelo qual a sociedade se adapta para poder incluir, em seus sistemas sociais gerais, pessoas com deficiência que se preparam para nela (sociedade) assumir seus papéis. Portanto, a inclusão social contribui para a construção de uma nova sociedade que, através de um processo de transformações nos ambientes físicos e na mentalidade das pessoas, passa a assimilar princípios como a aceitação das diferenças individuais, a valorização de cada pessoa, a convivência dentro da diversidade humana e a aprendizagem por meio da cooperação (SASSAKI, 1999).

A inclusão do aluno com deficiência no ensino superior já é uma realidade em algumas universidades brasileiras que desenvolvem com responsabilidade um trabalho de acessibilidade com objetivo de atender à legislação.

Inclusão digital

Entende-se o termo 'inclusão digital' como um meio de promover a melhoria da qualidade de vida, garantir maior liberdade social, gerar conhecimento e troca de informações, ou uma forma de facilitar $\mathrm{o}$ acesso às tecnologias, como o computador e Internet, por todas as pessoas, independentemente de sua condição física ou social. 
Atualmente, muitas informações úteis à população estão contidas em meios digitais ou em sites, devido à vantagem apresentada no seu armazenamento e recuperação, o que possibilita consultas rápidas, desde que seja possível o acesso a um computador ligado à Internet.

Conforme atesta Carvalho (2003, p.3):

"O acesso a essas máquinas e a seus conteúdos digitais não tem acontecido na intensidade que se esperava. A cada evolução da tecnologia digital, um contingente enorme de indivíduos deixa de ter acesso às informações que são armazenadas por meio da nova tecnologia. Esses indivíduos são denominados excluídos da sociedade da informação."

Dentre os fatores possíveis de exclusão digital, estão os ligados às limitações das pessoas com deficiência, como observa Sanches (1991, apud GIL, 2004, p. 161): "para a maioria das pessoas, a tecnologia torna a vida mais fácil. Para as pessoas com deficiência, a tecnologia torna a vida possível."

Para que haja possibilidade de acesso digital, a questão da infraestrutura que apoia os dispositivos a serem acessados é fundamental. Assim, o desenho acessível, que proporciona acesso exclusivo à pessoa com deficiência viabiliza o processo para esta camada da população. Já o desenho universal é mais completo, pois proporciona o uso da infraestrutura para todo e qualquer usuário, posto que o ambiente encontra-se adaptado a qualquer pessoa, tornandose mais democrático (SASSAKI, 1999).

\section{BIBLIOTECA UNIVERSITÁRIA}

A biblioteca universitária é um dos principais instrumentos da universidade para atingir suas finalidades - pesquisa, ensino e extensão. A biblioteca necessita de um acervo atualizado em diferentes suportes, servindo de apoio às pesquisas e investigações científicas, completando os conhecimentos ministrados nos cursos, valendose, para isso, de pessoal capacitado e em número suficiente, entre outros requisitos. (FERREIRA, 2003).
Cabe à biblioteca universitária, como órgão de apoio, possuir mão de obra especializada, contribuindo para a formação de uma sociedade mais justa, com oportunidades iguais de acesso às informações a todos. Deve dar continuidade ao trabalho iniciado na biblioteca escolar, completando os conteúdos ensinados em classe, oferecendo aos alunos mais recursos para adquirir informações que irão se transformar em conhecimentos.

\section{Serviços informacionais}

Os serviços informacionais são os desenvolvidos por uma biblioteca universitária, como o atendimento a consultas locais, serviços de empréstimo domiciliar e reserva de materiais. Outros são apresentados a seguir no quadro 1 , onde, na coluna 1 , estão listados os serviços de informação em bibliotecas universitárias e, na coluna 2, encontra-se a descrição dos serviços:

Segundo Ferreira (2003), mais importante que a estrutura física da biblioteca é o potencial humano. As bibliotecas universitárias necessitam de profissionais qualificados e capacitados para responder à demanda de novas ofertas de serviços, no atendimento de seus usuários no acesso à informação, e, embora possuir um bom acervo seja positivo, o fator humano é essencial.

\section{Bibliotecário/profissional da informação}

Em 1962 o governo federal dispôs, com a Lei $\mathrm{n}^{*}$ 4.084, de 30 de junho 1962, sobre a profissão de bibliotecário, e regulou seu exercício. A elaboração do código de ética da profissão se deu em 1963. A criação de cursos de pós-graduação em ciência da informação na década de 1970 reforçou a importância e a atualização da profissão no Brasil.

Segundo o Código de Ética Profissional do Bibliotecário (1986), elaborado pelo Conselho Federal de Biblioteconomia - Resolução no 327/86 - as atribuições profissionais no art. $3^{\circ}$ declaram que cumpre ao profissional de biblioteconomia: 
a) preservar o cunho liberal e humanista de sua profissão, fundamentado na liberdade da investigação científica e na dignidade da pessoa humana;

b) exercer a profissão, aplicando todo zelo, capacidade e honestidade no seu exercício;

c) cooperar intelectual e materialmente para o processo da profissão, mediante o intercâmbio de informações com associações de classe, escolas e órgãos de divulgação técnica e científica;

d) guardar sigilo no desempenho de suas atividades, quando o assunto assim exigir;

e) realizar, de maneira digna, a publicidade de sua instituição ou atividade profissional, evitando toda e qualquer manifestação que possa comprometer o conceito de sua profissão ou de colega;

f) considerar que o comportamento profissional irá repercutir nos juízos que se fizerem sobre a classe;

g) manter-se atualizado e cumprindo corretamente a legislação que rege o exercício profissional da biblioteconomia, colaborando para o aperfeiçoamento profissional;

h) combater o exercício ilegal da profissão.
Entende-se que estão implícitas nos itens "a" e " $g$ " do Código de Ética as preocupações com as pessoas com deficiência e a legislação a elas pertinente.

Obviamente, de acordo com Arruda, Marteleto e Souza (2000, p.19) "nenhum profissional tem condições de reunir todas as habilidades, conhecimentos e competências necessárias para interagir e equacionar os problemas decorrentes do fluxo de informação e conhecimento."

Em razão da existência de alunos com deficiência nas universidades, faz-se necessário um preparo especial na estruturação da biblioteca universitária para que a inclusão aconteça, permitindo aos alunos com deficiência condições de igualdade em sua formação e o seu reconhecimento enquanto cidadãos.

Existem trabalhos na literatura que abordam estudos de currículos no curso de biblioteconomia. Destacam-se dois: o estudo de Madruga (2007), abordando a importância de uma disciplina sobre a inclusão educacional, e a dissertação de Pando (2005), que faz uma análise comparativa dos conteúdos programáticos dos cursos de biblioteconomia, alertando para a necessidade de mudanças nos currículos para acompanhar as mudanças tecnológicas e a globalização.

\section{QUADRO 1}

\section{Serviços informacionais em bibliotecas universitárias}

\begin{tabular}{|c|c|}
\hline Serviços de informação & Descrição e característica \\
\hline Consulta rápida & $\begin{array}{l}\text { Serviço de informação em que o usuário consulta o } \\
\text { terminal de consulta, catálogo ou pessoa no atendimento }\end{array}$ \\
\hline Comut- Serviço de Comutação Bibliográfica & $\begin{array}{l}\text { Solicitação e fornecimento de cópias de artigos através } \\
\text { de meios eletrônicos }\end{array}$ \\
\hline Acesso à base de dados & $\begin{array}{l}\text { Recuperação de artigos de determinado assunto em } \\
\text { bases de dados on-line ou CD-Rom }\end{array}$ \\
\hline Empréstimo interbibliotecário & Empréstimos de materiais feitos entre bibliotecas \\
\hline $\begin{array}{l}\text { Orientação na normalização de trabalhos } \\
\text { acadêmicos }\end{array}$ & Orientação na elaboração de referências bibliográficas \\
\hline Treinamento de usuários & Recepção de calouros e visita orientada à biblioteca \\
\hline Ficha catalográfica & Elaboração de ficha em dissertações e teses \\
\hline
\end{tabular}

Fonte: Adaptado de Souza (2004) 
Na opinião de Nastri (1992, p.92),

o curso de graduação proporciona a base necessária para a atuação profissional, mas é importante que esse conhecimento adquirido seja aprofundado e constantemente atualizado. [...] É exigido do bibliotecário um conhecimento amplo, variado e sempre atualizado, que possibilite cumprir o seu papel de forma eficiente e adequada às constantes mudanças e exigências da sociedade.

Diante do exposto, confirma-se a necessidade de atualização profissional para acompanhar as mudanças que ocorrem na sociedade.

\section{O direito e a necessidade de acesso à informação}

Fonseca (1999) discorre sobre o direito à informação relacionando-o aos direitos humanos. Classifica os direitos do homem em duas classes: histórica e heterogênea. Com relação à classificação histórica, aponta os seguintes:

- direitos de primeira geração: são vistos como inerentes ao indivíduo, precedendo o contrato social (os direitos humanos contidos na Declaração Universal dos Direitos Humanos e dos Cidadãos de 1089). Fazem referência à liberdade de opinião;

- direitos de segunda geração: são os direitos de participação do bem-estar social, ou seja, direitos de crédito do indivíduo em relação à coletividade. Estão entre eles os direitos ao trabalho, à saúde e à educação. O titular desse direito continua sendo o homem na sua individualidade. $\mathrm{Na}$ complementaridade entre os direitos de primeira e segunda gerações, os últimos buscam assegurar as condições para o pleno exercício dos primeiros;

- os direitos de terceira e quarta gerações não têm como titular o indivíduo em sua singularidade, mas sim os grupos humanos, como a família, o povo, a nação, as coletividades regionais, as etnias e a própria humanidade. É o direito à paz, o direito ao desenvolvimento econômico, o direito ao meio ambiente.

Com relação à classificação heterogênea, afirma que entre os direitos do homem compreendidos nas declarações e nas leis há pretensões muito diversas entre si e até mesmo incompatíveis, concorrendo entre si e obrigando certas categorias de sujeitos a uma opção.

No contexto deste trabalho, que se refere ao acesso à informação em bibliotecas universitárias, seus autores entendem que o direito à informação está diretamente relacionado aos direitos de primeira e segunda gerações.

É importante citar, ainda, a seguinte afirmação de Fonseca (1999):

O elenco dos direitos do homem se modificou, e continua a se modificar, com a mudança das condições históricas, ou seja, dos carecimentos e dos interesses das classes no poder, dos meios disponíveis para a realização dos mesmos, das transformações técnicas, etc.

Com relação à necessidade do acesso à informação, observa-se que o período de transformações tecnológicas aceleradas marcou uma fase irreversível da história do ser humano. O repentino aumento de aplicações tecnológicas transformou os processos de produção e distribuição de bens e de serviços, criando grande quantidade de produtos e serviços que ficavam ao alcance de poucos países e elites que dominavam as tecnologias, influenciando de maneira decisiva a localização da riqueza e do poder no mundo (CASTELLS,1999).

Com o fim da Segunda Guerra Mundial, houve forte desenvolvimento tecnológico; surgiram os computadores e a ciência e a organização da informação receberam influências que levaram a mudanças significativas no tratamento da informação. As pesquisas se conectaram na busca de soluções para os problemas advindos da explosão informacional tratada no artigo clássico de Bush (1945) As we may think, onde é definido o problema do gerenciamento da informação e proposta uma máquina como solução, denominada Memex, que aproveitaria as mais modernas tecnologias de informação existentes na época. $\mathrm{Na}$ realidade, o Memex nunca foi construído, mas a ideia serviu como inspiração a pesquisadores e cientistas 
para o desenvolvimento de novas tecnologias de informação (BUSH, 1945).

Portanto, para Bush (1945), as tecnologias existentes em sua época, se fossem desenvolvidas de maneira correta, permitiriam ao ser humano o acesso e o controle de todo conhecimento existente há séculos. Sua visão era fantástica, anteviu o avanço tecnológico que facilitaria a recuperação da informação, os computadores, base de dados e a própria Internet.

Le Coadic (2004) questiona: o que leva uma pessoa a procurar informação. Entre as razões que considera, destaca três:

- problemas para resolver;

- objetivo a atingir;

- constatação de um conhecimento insuficiente ou inadequado.

A necessidade de informação é considerada uma necessidade fundamental do ser humano. Portanto, para suprir essa necessidade do acesso à informação deve ser sempre orientado aos usuários, atendendo a suas necessidades.

Acesso e recuperação da informação

O processo de acesso e recuperação de informação consiste em identificar um conjunto de documentos sobre determinado assunto, disponibilizando e permitindo ao usuário uma rápida seleção dos itens que satisfarão sua necessidade de informação.

A Declaração da Ifla (1999) sobre as bibliotecas e a liberdade intelectual foi apresentada e aprovada em 25 de março de 1999. Em suma, destacam-se os seguintes itens:

- a Ifla crê no direito à liberdade de expressão e o direito ao saber como requisito para a liberdade de pensamento e de consciência; a liberdade de pensamento e a liberdade de expressão são condições necessárias para a liberdade de acesso à informação;

- as bibliotecas têm a responsabilidade de garantir e de facilitar o acesso às manifestações do conhecimento e da atividade intelectual;
- as bibliotecas tornarão acessíveis, a todos os usuários, todos os materiais e os serviços. Não haverá discriminação por razão de raça, religião, sexo, idade ou por qualquer outro motivo (Ifla, 1999).

Barreiras encontradas no acesso à informação

A escolha da melhor estrutura que proporcione o uso democrático dos espaços deve transpor ainda algumas dificuldades encontradas para o acesso à informação.

Carvalho (1998) exemplifica tipos de barreiras quando cita o caso do acesso de aluno com deficiência visual ao vestibular à PUC-Campinas, à literatura de apoio às disciplinas, ao uso de laboratórios para acompanhamento das aulas, na realização de provas com a classe, além da socialização e locomoção dentro do próprio espaço do campus. Estas dificuldades são realidades e devem ser resolvidas por meio de estratégias que façam da inclusão prioridade com direitos iguais para todos.

Observa-se que as barreiras citadas envolvem o acesso físico ao ambiente do câmpus universitário e à biblioteca, situações estas passíveis de solução se houver vontade política, organização do espaço e condições apropriadas à clientela heterogênea que deseja e necessita estudar.

Tecnologias de informação aplicadas ao aluno com deficiência

O objetivo do uso de tecnologias de informação é o de incluir o aluno com deficiência no ensino superior e na sociedade do conhecimento com autonomia e independência.

O uso de tecnologias ajuda o cumprimento da Portaria n. 1.679, de 2/12/1999, que diz que a instituição deve proporcionar, caso seja solicitada, desde o acesso até a conclusão do curso, sala de apoio e equipamentos necessários para facilitar a vida acadêmica do aluno com deficiência, promovendo sua autonomia dentro do câmpus (PUPO, 2006). 
As tecnologias assistivas são recursos e serviços que têm como objetivo facilitar a vida de pessoas com deficiência e são utilizadas "para auxiliar na locomoção, no acesso à informação e na comunicação, no controle do ambiente e em diversas atividades do cotidiano, como estudo, o trabalho e o lazer."(MELO, COSTA, SOARES, 2006, p.62). Exemplos de tecnologias assistivas: cadeiras de rodas, bengalas, órteses e próteses, lupas, aparelhos auditivos e controles remotos, software leitores de telas de computadores, entre outros.

Os equipamentos podem facilitar a vida acadêmica do aluno com deficiência. Portanto, a biblioteca universitária pode proporcionar um bom atendimento, devendo para isso ser equipada com tecnologias assistivas tal como nos modelos apresentados a seguir, de duas bibliotecas consideradas pela literatura como acessíveis.

\section{Bibliotecas acessíveis}

O conceito de biblioteca acessível, segundo Gonzalez (2002), engloba a questão de acessibilidade física e virtual, um serviço de referência adequado orientando os usuários no uso da informação. É importante fazer diferença entre biblioteca acessível e biblioteca adaptada. Biblioteca adaptada é aquela que segue as regras do desenho acessível, com rampas, banheiros adaptados, sinaleiras Braille, entre outras. A biblioteca acessível é a que disponibiliza a informação em qualquer suporte e provê acesso a todas as pessoas que dela necessitam, ou seja, segue os princípios do desenho universal.

Citados como referência na literatura da área, ciência da informação, encontram-se dois programas de acessibilidade que são apresentados como base para o estudo do funcionamento e bom atendimento ao aluno com deficiência na biblioteca universitária. São eles o ProAces/DV da PUC de Campinas e o Laboratório de Acessibilidade (LAB) - Unicamp.

\section{PUC-Campinas}

De acordo com Carvalho (1999), o Projeto de Acessibilidade aos Alunos Deficientes Visuais (ProAces/DV) da PUC-Campinas foi criado em
1997 por um grupo multidisciplinar de trabalho, para viabilizar o atendimento de alunos deficientes visuais que haviam ingressado na universidade.

O grupo foi formado por representantes do Instituto de Informática; Instituto de Psicologia e Fonoaudiologia; Faculdade de Educação; Centro Interdisciplinar de Apoio ao Deficiente, além de representantes dos alunos com deficiência visual da universidade. Seu objetivo é fornecer a infraestrutura necessária para melhorar a acessibilidade e a integração dos alunos com deficiência visual na universidade, de forma profissional e padronizada.

Segundo Carvalho e Aranha (1998), o ProAces/ DV oferece monitoria pessoal ao aluno com deficiência visual, e o Centro de Acessibilidade ao aluno deficiente visual (CA/DV), que consiste de um conjunto de dispositivos de tecnologia computacional dedicados a aumentar a acessibilidade dos seus usuários. Tem como objetivo permitir o acesso dos deficientes visuais a toda forma de informação digitalizada.

Atualmente, o projeto foi estendido aos alunos com qualquer tipo de deficiência.

A biblioteca da PUC-Campinas desenvolve um trabalho de assistência ao aluno com deficiência, em conjunto com o ProAces, disponibilizando um bibliotecário e um técnico em biblioteca para acompanhar o usuário até as estantes e fornecer orientação no uso do acervo dos equipamentos acessíveis disponíveis da biblioteca.

\section{Laboratório de Acessibilidade - Unicamp}

O Laboratório de Acessibilidade (LAB) - Unicamp teve início em 1998, mas foi implantado em dezembro de 2002, na Biblioteca Central, como laboratório de apoio didático, visando o acesso ao conhecimento de todos os usuários, mediados por recursos tecnológicos, oferecendo ambiente adequado aos usuários com necessidades especiais no acesso à informação (PUPO; CARVALHO; CHAVES, 2003).

Ci. Inf., Brasília, DF, v. 38, n. 3, p.64-79, set./dez., 2009 
O LAB surgiu, a princípio, para cumprir a legislação brasileira de acessibilidade: proporcionar um ambiente adequado aos usuários da Unicamp com deficiência, garantindo direitos de acesso a serviços e produtos que permitam sua inclusão na sociedade do conhecimento com autonomia.

São objetivos do LAB:

- promover acessibilidade aos serviços e produtos;

- disponibilizar os equipamentos aos usuários para estudos, pesquisa e lazer;

- promover apoio didático conforme disponibilidade dos equipamentos e recursos humanos;

- orientar quanto ao uso das TICs;

- proporcionar um ambiente adequado aos usuários, pesquisadores e estudiosos em inclusão e acessibilidade;
- possibilitar a criação e disseminação de novas ferramentas de apoio que complementem a educação dos usuários com deficiência;

- divulgar os produtos e serviços interna e externamente;

- estimular a autonomia acadêmica de seus usuários;

- produzir material adaptado (PUPO, 2006, p.57).

A seguir, apresenta-se o quadro 2 - Serviços de acessibilidade oferecidos (LAB/Unicamp). $\mathrm{Na}$ coluna 1 encontram-se os tipos de serviços oferecidos e na coluna 2 o profissional que executa o serviço no atendimento ao aluno com deficiência.

Observou-se nas bibliotecas apresentadas que os objetivos comuns são os de suprir as necessidades dos alunos com deficiência ao ingressarem no ensino superior, promovendo o acompanhamento durante sua permanência na universidade. Certamente é um começo, que deve continuar ampliando seus serviços e produtos.

QUADRO 2

Serviços de acessibilidade oferecidos (LAB/Unicamp)

\begin{tabular}{l|c}
\multicolumn{1}{c|}{ Serviços oferecidos } & Funcionários \\
\hline Orientação à pesquisa bibliográfica & Bibliotecário \\
\hline Levantamentos bibliográficos & Bibliotecário \\
\hline Localização e obtenção de materiais bibliográficos & Bibliotecário \\
\hline $\begin{array}{l}\text { Orientação e normalização de dissertações e teses, trabalhos de graduação, } \\
\text { artigos para publicação em periódicos científicos }\end{array}$ & Bibliotecário \\
\hline $\begin{array}{l}\text { Capacitação dos usuários no uso adequado das fontes de informação } \\
\text { disponíveis }\end{array}$ & Bibliotecário \\
\hline $\begin{array}{l}\text { Capacitação dos usuários no uso adequado das fontes de informação } \\
\text { disponíveis }\end{array}$ & Bibliotecário \\
\hline Transcrição de textos em Braille & Pedagogo \\
\hline Reprodução de texto em tinta para o sistema Braille & Pedagogo \\
\hline Adaptações de avaliações & Pedagogo \\
\hline \multicolumn{1}{c|}{ Serviços andamento a partir de 2008 } & Bibliotecário \\
\hline Digitalização: escaneamento e correção & Bibliotecário \\
\hline Encaminhamento ao usuário por e-mail & \\
\hline Normatização das referências dos textos para inserção no portal doLAB & \\
\hline
\end{tabular}

Fonte: adaptado de PUPO (2006)

Ci. Inf., Brasília, DF, v. 38, n. 3, p.64-79, set./dez., 2009 
PROPOSTA DE DISCIPLINA PARA CURSOS DE GRADUAÇÃO EM BIBLIOTECONOMIA

A portaria no 1.793 do MEC (BRASIL, 1994), recomenda, aos cursos superiores que formam profissionais que atuam com pessoas com deficiência, a inclusão, na matriz curricular, da disciplina Aspectos Ético-Político-Educacionais da Normalização e Integração da Pessoa Portadora de Necessidades Especiais.

Sendo o curso de biblioteconomia um curso de formação profissional de bibliotecários que irão interagir, também, com pessoas com deficiência, na busca por informação em bibliotecas, entende-se que seja de fundamental importância a apresentação de conteúdos que os preparem para um atendimento de qualidade, de acordo com as recomendações da Portaria $\mathrm{n}^{\circ} 1.793$.

Chacon (2004) apresenta o resultado de uma pesquisa realizada em 2001, sobre a análise das grades curriculares e ementas de 33 cursos de graduação de pedagogia e psicologia, a fim de verificar o cumprimento da recomendação da Portaria $\mathrm{n}^{\circ} 1.793$.

Apenas a portaria no 1.793 e Chacon (2004) não são suficientes para a proposta de uma disciplina na área de biblioteconomia. Sentiu-se, então, a necessidade de usar algumas soluções que servissem de referência para verificar o conteúdo ideal a ser oferecido por uma disciplina que pudesse capacitar o bibliotecário para $\mathrm{o}$ atendimento às pessoas com deficiência. Optou-se pela construção de um quadro que abrangesse os diversos aspectos relativos à acessibilidade tratados nesta pesquisa.

A figura 1 ilustra o processo de formação do quadro de referência (quadro 3) e nela são apresentados os conteúdos referenciados neste trabalho com os capítulos que os justificam.

A seguir encontra-se o quadro 3, onde são indicados, na coluna 1 , os conteúdos de referência que uma proposta de disciplina deve contemplar e, na coluna 2, os itens desta pesquisa nos quais se apoiam.

FIGURA 1

Processo de formação do quadro de referência

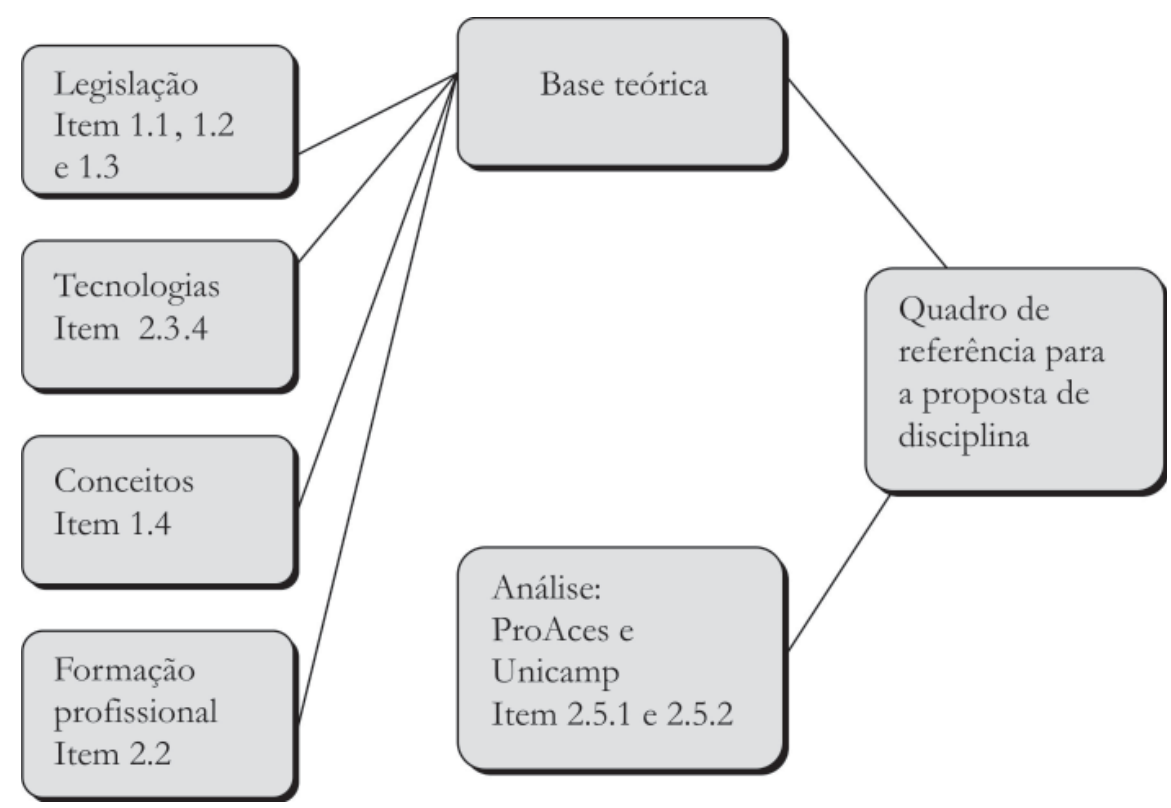

Fonte: Autores, 2008 
QUADRO 3

\section{Quadro de referência}

\begin{tabular}{l|l}
\multicolumn{1}{c|}{ Conteúdos } & Baseado em \\
\hline Histórico da deficiência & Item 1.1 \\
\hline $\begin{array}{l}\text { Legislação nacional e } \\
\text { internacional }\end{array}$ & Itens 1.2 e 1.3 \\
\hline Tipos de deficiência & Item 1.4.1 \\
\hline Acessibilidade & Item 1.4.2 \\
\hline Inclusão social & Item 1.4.3 \\
\hline Inclusão digital & Item 1.4.4 \\
\hline Tecnologias de apoio & Item 2.3.4 \\
\hline $\begin{array}{l}\text { Serviços oferecidos em } \\
\text { bibliotecas acessíveis }\end{array}$ & Itens 2.5.1 e 2.5.2 \\
\hline Aspectos éticos & Item 2.2 \\
\hline $\begin{array}{l}\text { Preparo profissional } \\
\text { (bibliotecário) }\end{array}$ & Itens 2.2 \\
\hline
\end{tabular}

Fonte: Autores, baseados nos resultados da análise de dados da pesquisa, 2008

A partir do exposto, seguem os itens relativos a uma proposta de disciplina que visa a incluir, na formação do profissional da área de biblioteconomia, conteúdo sobre a acessibilidade à informação.

\section{Ementa}

No trabalho desenvolvido por Chacon, há uma sugestão de ementa de

disciplinas a serem implantadas ou reestruturadas, tendo claro, evidentemente, suas limitações que devem ser supridas pelas especificidades de cada curso, bem como pelo referencial teórico metodológico do profissional que irá ministrá-la. (CHACON, 2004, p.334).

Optou-se neste trabalho por acatar a sugestão de Chacon, uma vez que a ementa sugerida ajusta-se com pequenas adaptações à proposta deste trabalho.

A disciplina objetiva a reflexão crítica do futuro profissional sobre:

a) o posicionamento político e ético da sociedade envolvendo as pessoas com deficiência;

b) as especificidades das deficiências e sua relação com as perspectivas atuais e históricas da inclusão educacional; c) as políticas públicas de inclusão no ensino superior, diante da cultura de diversidade em que diferenças individuais são oportunidades de aprender, de produzir e construir conhecimento a partir das diferenças;

d) aspectos teóricos e práticos das tecnologias de acesso à informação e qualidade do serviço ao usuário. (CHACON, 2004).

\section{Objetivo geral}

Capacitar o aluno do curso de biblioteconomia, preparando-o para melhor atender à demanda e cumprir as exigências da legislação nacional, reconhecendo a importância do atendimento da pessoa com deficiência na biblioteca universitária.

\section{Objetivos específicos}

- descrever a trajetória histórica da inclusão escolar e suas implicações culturais e sociais;

- analisar a legislação que fundamenta e ampara a pessoa com deficiência;

- definir conceitos de deficiência e suas características identificando as principais barreiras no atendimento às pessoas com deficiência;

- conhecer recursos específicos do uso de tecnologias de informação para tornar possível o acesso à informação em bibliotecas universitárias de pessoas com deficiência;

- estudar linguagens alternativas de comunicação

\section{Conteúdo Programático}

- Retrospectiva histórica da deficiência através dos tempos

- Legislação internacional

a) Declaração de Direitos humanos, 1948

b) Declaração dos Direitos das Pessoas com Deficientes, 1975

c) Declaração de princípios, 1981

d) Declaração Mundial sobre Educação para todos, 1990 
e) Declaração de Salamanca, 1994

f) Declaração de princípios sobre a tolerância, 1995

g) Convenção da Guatemala, 1999

h) Carta para o Terceiro Milênio, 1999

i) Declaração de Madri, 2002

j) Declaração de Caracas, 2002

k) Declaração de Quito, 2003.

- Legislação nacional

a) Constituição Federal de 1988

b) Lei n. 8.069, 1990

c) Lei n. 9.394, 1996

d) Lei n. 9.610, 1998

e) Portaria n. 1.679, 1999

f) Decreto n. 3.298, 1999

g) Lei n. 10.048, 2000

h) Lei n. 10.098, 2000

i) Lei n. 10.172, 2001

j) Decreto n. 3.956, 2001

k) Parecer n. 17/2001.

- Políticas públicas de inclusão no ensino superior

a) Decreto n. 5.296 de 2004 - Programa Incluir, acessibilidade na educação superior

- Definição e características das condições

a) deficiência visual;

b) deficiência auditiva;

c) deficiência física;

d) deficiência mental;

e) deficiência múltipla.

- Bibliotecário/Profissional da informação

a) serviços informacionais;

b) ética.
- Principais formas de atendimento àpessoa com deficiência

a) dicas de comportamento para o atendimento da pessoa com NEE;

b) desenho universal.

- Informática como instrumento facilitador no acesso à informação

a) acessibilidade;

b) inclusão digital e o acesso à informação;

c) conhecer as tecnologias assistivas - equipamentos e softwares (Dosvox, Virtual vision, Jaws for Windwons, etc);

d) serviços em bibliotecas universitárias acessíveis.

- Linguagens de comunicação alternativa

a) braille - histórico e noções do alfabeto;

b) libras - histórico e termos técnicos.

\section{Metodologia de ensino}

Aulas expositivas; seminários; dinâmica de grupos; utilização de recursos audiovisuais e práticas de laboratório.

\section{CONSIDERAÇÕES FINAIS}

O principal objetivo deste trabalho de pesquisa, em síntese, foi propor uma disciplina aos cursos de graduação em biblioteconomia, com ementa, objetivos, metodologia e bibliografia, que auxilie no preparo do bibliotecário para tornar a biblioteca universitária acessível.

Para tanto, realizou-se primeiramente uma pesquisa bibliográfica para o embasamento teórico de conceitos como deficiência, inclusão social, inclusão digital e acessibilidade, necessários para o entendimento das dificuldades encontradas pelos alunos com deficiência no acesso à informação em bibliotecas universitárias.

Diante disso, buscou-se estabelecer a situação da pessoa com deficiência na sociedade através da existência de legislação, de programas do governo e 
de bibliotecas universitárias acessíveis. Apresentamse serviços possíveis oferecidos a alunos com deficiência em dois programas universitários, a saber, o ProAces da PUC-Campinas e o LAB da Unicamp.

Um ensino de qualidade deve estar disponível para todos os indivíduos que desejam ascender a um patamar mais elevado no processo educacional, por isso, devem ser utilizados todos os recursos disponíveis que tornam o acesso à informação possível. Os profissionais que trabalham em bibliotecas universitárias devem ser treinados para serem capazes de participar do processo de inclusão desses alunos. Só assim as barreiras de acesso à informação serão derrubadas.

Foram apresentados um breve histórico da deficiência; os principais documentos relacionados à acessibilidade e a importância da inclusão social e da inclusão digital para assegurar o acesso à informação do aluno com deficiência, fazendo uso de tecnologias assistivas. Foram discutidos os fundamentos que confirmam a relevância do tema abordado na pesquisa, como a pessoa com deficiência e o acesso à informação, que complementa a essencialidade do tema em pauta, para que se compreendam os reais objetivos desta proposta.

Salientou-se a importância da biblioteca dentro da universidade. Em resposta à contribuição para a formação do bibliotecário no que se refere a serviços especiais em bibliotecas universitárias, apresentou-se o bibliotecário, suas atribuições e serviços informacionais oferecidos em bibliotecas universitárias. Foram descritos dois programas de acessibilidade em bibliotecas universitárias (ProAces e LAB), e quais as tecnologias e serviços oferecidos ao aluno com deficiência.

Finalmente, tem-se a principal contribuição do estudo realizado. Foi necessário o desenvolvimento de um quadro de referência (quadro 3) que permitisse a comparação dos resultados da pesquisa com o estudo do referencial teórico. Com base nos resultados obtidos, impulsionou-se a sugestão da proposta de uma disciplina de acessibilidade à informação com o objetivo de contribuir para a formação do bibliotecário, preparando o profissional para atender à demanda em bibliotecas universitárias no que diz respeito ao atendimento de alunos com deficiência.

Entende-se que os resultados da pesquisa confirmam a necessidade de capacitar o bibliotecário na área de acessibilidade em bibliotecas universitárias para atender à demanda. Confirma-se também a importância, para a ciência da informação e a biblioteconomia, em oferecer tal disciplina para formação profissional. Espera-se que as reflexões aqui apresentadas possam contribuição para o campo da ciência da informação e da biblioteconomia.

Por fim, é oportuno ressaltar que a formação do bibliotecário se reflete em sua postura diante das transformações sociais ou tecnológicas que se apresentam no seu desempenho profissional. Por isso, considera-se que a acessibilidade deve aparecer na sua formação.

Artigo submetido em 23/03/2009 e aceito em 29/01/2010.

\section{REFERÊNCIAS}

ARRUDA, Maria Conceição Calmon; MARTELETO, Regina Maria; SOUZA, Donaldo Bello de. Educação, trabalho e o delineamento de novos perfis profissionais: o bibliotecário em questão. Ciência da Informação, Brasília, v. 29, n.3, p.14-24, set./dez., 2000.

BRASIL. MINISTÉRIO DA EDUCAÇÂO E CULTURA. Portaria n. 1.793 de 27/12/1994: recomendação: formação de recursos humanos em educação especial. Disponível em: http://portal.mec.gov.br/ arquivos/pdf/portaria1793.pdf. Acesso em: 24 set, 2008.

BUSH, V. As we may think. Atlantic Monthly, v.176, n.1, p.101-108, 1945.

CARVALHO, José Oscar Fontanini de. O papel da interação humanocomputador na inclusão digital. Transinformação, Campinas: v. 15, p. 75-89, set./dez., 2003. Edição especial.

CARVALHO, José Oscar Fontanini de. A tecnologia apoiando os deficientes visuais no ensino superior - a experiência da PUC-Campinas. In: Mídia, educação e leitura. BARZOTTO, Valdir; GHILARD, Maria Inês (Orgs.). São Paulo: Anhembi Morumbi: Associação de Leitura do Brasil, 1999. p. 229-240.

; ARANHA, Maria Cristina L.F.M. ProAces/DV: projeto de acessibilidade aos alunos deficientes visuais da PUC Campinas: aspectos tecnológicos. In: CONGRESSO NACIONAL DA SOCIEDADE BRASILEIRA DE COMPUTAÇÃO. 18., Belo Horizonte. IV Workshop de informática na escola, 1998. Anais... Belo Horizonte, UFMG, 1998.v. 1, p. 557-567. Disponível 
em: <http://docentes.puc-campinas.edu.br/ceatec/oscar/pdfs/ carvalho98a.PDF>. Acesso em: 4 mar. 2008.

CASTELLS, Manuel. A sociedade em rede. 3.ed. São Paulo : Paz e Terra, 2000 . v.1.

CHACON, Miguel Claúdio Moriel. Formação de recursos humanos em educação especial: resposta das universidades à recomendação da portaria ministerial n. 1.793. Revista Brasileira de Educação Especial, Marília, v. 10, n. 3, p. 321-336, set./dez., 2004.

CONSELHO FEDERAL DE BIBLIOTECONOMIA. Código de Ética Profissional do Bibliotecário. (1986). Disponível em: < http:/ /www. cfb.org.br/legislacao/resolucoes/Resolu \%C3\%A7\%C3\%A3o\%20 04202.asp>. Acesso em: 30 abr. 2008.

FERREIRA, Danielle Thiago. Profissional da informação: perfil de habilidades demandadas pelo mercado de trabalho. Ciência da Informação, Brasília, v. 32, n. 1, p. 42-49, 2003.

FONSECA, Maria Odila. Informação e Direitos Humanos: acesso às informações arquivísticas. Ciência da Informação, Brasília, v. 28, n. 2, 1999.

GIL, Marta Esteves de Almeida. Inclusão digital e inclusão social: o papel da acessibilidade. In: OMOTE, Sadao (Org.). Inclusão: intenção e realidade. Marília: Fundepe, 2004. p. 159-166.

GONZALEZ, Camilla J. Biblioteca acessivel: serviço de informação para usuários com deficiência. 2002. Monografia (Departamento de Biblioteconomia e Documentação) - ECA, USP, 2002. Disponível em: <http://www.saci.org.br $/$ modulo=akemi\&parametro $=4716>$. Acesso em: 22 set. 2005.

INTERNATIONAL FEDERATION OF LIBRARY ASSOCIATIONS. Declaração da IFLA sobre as bibliotecas e a liberdade intelectual. 25 de março de 1999. Disponível em: http://www.ifla. org/V/press/p90326s.htm. Acesso em: 4 de mar. 2008.

LE COADIC, Y. A Ciência da Informação. 2. ed. Brasília, DF: Briquet de Lemos, 2004.

MADRUGA, Maria Lúcia Cazarin Beserra. Biblioteconomia e inclusão educacional: análise de propostas curriculares. In: SEMINÁRIO NACIONAL DE BIBLIOTECAS BRAILLE, 5., 23 e 24 de novembro de 2007, Florianópolis. 1 CD-Rom.

MELO, Amanda Meincke; COSTA, Jean B. da; SOARES, Sílvia C. de M. Tecnologias assistivas. In: PUPO, Deise Tallarico; MELO, Amanda Meincke; FERRÉZ, Sofia Péréz (Org.) Acessibilidade: discurso e prática no cotidiano das bibliotecas. Campinas: UNICAMP, 2006. p. 62-70.

NASTRI, Rosemeire Marino. Formação profissional do bibliotecário no Brasil sob perspectiva histórico-educacional. Revista Brasileira de Biblioteconomia e Documentação, São Paulo, v. 25, n. 3 / 4, p. 79-96, jul./ dez. 1992.

OMOTE, Sadao. Inclusão: da intenção à realidade. In: OMOTE, Sadao (Org.). Inclusão: intenção e realidade. Marília: Fundepe, 2004. p. 1-9.

PANDO, Daniel Abraão. Formação e demanda profissional em tratamento temático da informação no Brasil: uma análise comparativa de conteúdos programáticos universitários e de concursos públicos em
Biblioteconomia. 2005. Dissertação (Mestrado) - UNESP, Marília, 2005. Disponível em: <http://polo1.marilia.unesp.br/Home/Posgraduacao/CienciadaInformacao/Dissertacoes/pando_da_me_mar. pdf> Acesso em: 28 abr., 2008.

PEREIRA, Bárbara. Respeito à diversidade humana: distância entre intenção e gesto. In: OMOTE, Sadao (Org.). Inclusão: intenção e realidade. Marília: Fundepe, 2004. p. 145-157.

PUPO, Deise Tallarico; MELO, Amanda Meincke; FERRÉZ, Sofia Péréz. (Org.) Acessibilidade: discurso e prática no cotidiano das bibliotecas. Campinas: UniCamp, 2006.

; CARVALHO, Sílvia H.; CHAVES, Maycon. Laboratório de acessibilidade/BC UNICAMP. In: SEMINÁRIO ATIID, 2., 23-24 de set., 2003, São Paulo. Acessibilidade, TI e inclusão digital. Disponível em: <http://www.fsp.usp.br/acessibilidade/cd/atiid2003/artigos/ posters/P4_LAB.pdf>. Acesso em: 4.maio 2008.

; VICENTINI, Regina Aparecida Blanco. A integração do usuário portador de deficiência às atividades de ensino pesquisa: o papel das bibliotecas virtuais. In: SEMINÁRIO NACIONAL DE BIBLIOTECAS UNIVERSITÁRIAS, 10., 1998, Fortaleza. Anais... Fortaleza: UFCe; UNIFOR, 1998. Disponível em: < http://libidigi. unicamp.brdocument $/$ ?code $=1122>$. Acesso em: 23 set. 2005 .

ROCHA, Heloísa Vieira da; BARANAUSKAS, Maria Cecília Calani. Design e avaliação de interfaces humano-computador. Campina: NIED/ UniCamp, 2003. Disponível em: < http://www.nied.unicamp.br/ publicacoes $/$ pub.phpclasse $=$ livro\&cod_publicacao $=73>$ Acesso em 2 de maio de 2008

SASSAKI, Romeu Kazumi. Inclusão: construindo uma sociedade para todos. 3.ed. Rio de Janeiro: WVA, 1999.

SOUZA, Salete Cecília de. Acessibilidade: uma proposta de metodologia de estruturação de serviços informacionais para usuários cegos e com visão sub-normal em biblioteca Universitária. Dissertação (Departamento de Pós-Graduação em Engenharia de Produção) - UFSC, 2004. Disponível em: <http://www.uem.br/redirect. phpto $=$ wwwbce.uem.br $>$. Acesso em: 22 set. 2005.

\section{BIBLIOGRAFIA SUGERIDA}

ACESSIBILIDADE BRASIL. Disponível em: $<$ http://www. acessobrasil.org.br/> Acesso em 18 de maio de 2008.

AMARAL, L. A. Pensar a diferenca: deficiência. Brasília: CORDE, 1994. BAUMEL, Roseli C.R. de C.; SEMEGHINI, I (orgs.). Integrar/Incluir: desafios para a escola atual. São Paulo: FEUSP, 1998.

BRASIL. Estatuto da Criança e do adolescente Disponível em: http:// www.planalto.gov.br/ccivil_03/Leis/L8069.htm> Acesso em 18 de maio de 2008.

BRASIL. DECRETO n. 5296 de 2 de dezembro de 2004. Disponível em: $<$ http://www010.dataprev.gov.br/sislex/paginas/23/2004/5296. $\mathrm{htm}>$ Acesso em 18 de maio de 2008.

BRASIL. DECRETO n. 3.298, de 20 de dezembro de 1999. Regulamenta a Lei n. 7.853, de 24 de outubro de 1989, dispõe

Ci. Inf., Brasília, DF, v. 38, n. 3, p.64-79, set./dez., 2009 
sobre a Política Nacional para a Integração da Pessoa Portadora de Deficiência, consolida as normas de proteção, e dá outras providencias. Disponível em: http://www010.dataprev.gov.br/sislex/ paginas/23/1999/3298.htm. Acesso em: 09 de maio de 2008.

BRASIL. Lei n. 7.853 de 24 de outubro de 1989. Dispõe sobre o Apoio às pessoas portadoras de deficiências, sua integração social, Coordenadoria Nacional para Integração da Pessoa Portadora de Deficiência - CORDE. Disponível em: http://www010.dataprev. gov.br/sislex/paginas/42/1989/7853.htm. Acesso em: 9 de maio de 2008 .

BRASIL. Lei n. 10.098, de 19 de dezembro de 2000. Estabelece normas gerais e critérios básicos para a Promoção da acessibilidade das pessoas portadora de deficiência ou com mobilidade reduzida e dá outras providências. Disponível em: http://www.planalto.gov. br/CCIVIL/LEIS/L10098.htm. Acesso em: 9 de maio de 2008.

BRASIL. MINISTÈRIO da EDUCAÇÂO E CULTURA. Educação superior Cursos e Instituições. Cadastros de instituiç̃es de Educação Superior. Disponível em: <http://www.educacaosuperior.inep.gov. br/funcional/lista_cursos.asp >. Acesso em: fev. 2007 e ago 2008.

BRASIL. MINISTÉRIO de ESTADO e da EDUCAÇÃO e do DESPORTO. Portaria n. 1.793 de 27/12/1994. Recomendação: Formação de recursos humanos em educação especial. Disponível em: http://portal.mec.gov.br/arquivos/pdf/portaria1793.pdf. Acesso em 24 de set, 2008.

BRASIL. MINISTÈRIO da EDUCAÇÂO E CULTURA. Portaria n. 3.284. de 7/11/1999. Dispõe sobre requisitos de Acessibilidade de pessoas portadoras de deficiência, para instruir os processos de autorização e de reconbecimento de cursos e de credenciamento de instituições. Disponível em: http://portal.mec.gov.br/sesu/arquivos/pdf/port3284.pdf. Acesso em: 09 de maio de 2008.

BRASIL. MINISTÈRIO da EDUCAÇÂO E CULTURA. Portaria n. 1.679. de 2 de dezembro de 1999. Dispõe sobre requisitos de acessibilidade de pessoas portadoras de deficiência, para instruir os processos de autorização e de reconhecimento de cursos e de credenciamento de instituições. Disponível em: http://portal.mec. gov.br/sesu/arquivos/pdf/portarias/p1679.pdf. Acesso em: 09 de maio de 2008

BRASIL. MINISTERIO DE EDUCAÇÂO E CULTURA. Programa Incluir. Disponível em:http://portal.mec.gov.br/sesu/index.php?op tion $=$ content $\&$ task $=$ view\&id $=557 \&$ Itemid $=303>$. Acesso em: 04 de maio 2008.

CARVALHO, José Oscar Fontanini de. Solucõoes tecnológicas para viabilizar o acesso do deficiente visual à educação a distância no ensino superior. 2001. Tese (Doutorado) - Universidade Estadual de Campinas, 2001.

CARVALHO, José Oscar Fontanini de. A tecnologia apoiando os deficientes visuais no ensino superior - a experiência da PUCCampinas. In: Mídia, educação e leitura. (Org.) Valdir Barzotto, Maria Inês Ghilard. São Paulo: Anhembi Morumbi: Associação de Leitura do Brasil, 1999. p. 229-240.
CARVALHO, José Oscar Fontanini de; ARANHA, Maria Cristina L.F.M.. ProAces/DV - Projeto de acessibilidade aos alunos deficientes visuais da PUC-Campinas - Aspectos Tecnológicos.1998. Anais do XVIII Congresso Nacional da Sociedade Brasileira de Computação, IV Workshop de informática na Escola, Belo Horizonte, MG, Universidade Federal de Minas Gerais, v. 1, p.557-567. Disponível em: <http://docentes.puc-campinas.edu.br/ceatec/oscar/pdfs/ carvalho98a.PDF>. Acesso em: 04. mar. 2008.

CHACON, Miguel Claúdio Moriel. Formação de recursos humanos em educação especial: resposta das universidades à recomendação da portaria ministerial n. 1.793. Revista Brasileira de Educação Especial, Marília, v.10, n.3, p.321-336, set./dez., 2004.

DIAS, Claudia. Usabilidade na WEB: criando portais mais acessíveis. Rio de Janeiro : Alta Books.

FONSECA, V. da. Educação especial. Porto Alegre: Artes Médicas, 1995.

FREIRE, Paulo. Pedagogia da autonomia: saberes necessários à pràtica educativa. São Paulo: Paz e Terra, 1996.

MARTINS, Lúcia de Araujo R (org.). Inclusão: compartilhando saberes. 2.ed. Petrópolis: Vozes, 2006.

MAZZOTTA, M.J.S. Educação especial no Brasil: história e políticas públicas. São Paulo: Cortez, 1999.

MILLER, N.B Ninguém é perfeito: vivendo e crescendo com crianças que tem necessidades especiais. Campinas: Papirus, 1995.

OMOTE, Sadao. Inclusão: da intenção à realidade. In: OMOTE, Sadao (Org.). Inclusão: intenção e realidade. Marília: Fundepe, 2004. p.1-9.

PUPO, Deise Tallarico; MELO, Amanda Meincke; FERRÉZ, Sofia Péréz. (Org.) Acessibilidade: discurso e prática no cotidiano das bibliotecas. Campinas: UNICAMP, 2006.

PUPO, Deise Tallarico; CARVALHO, Sílvia H.; CHAVES, Maycon. Laboratório de acessibilidade?BC UNICAMP. In: Seminário ATIID, II - Acessibilidade, TI e inclusão digital, São Paulo, 23-24 de set., 2003. Disponível em: <http://www.fsp.usp.br/acessibilidade/cd/ atiid2003/artigos/posters/P4_LAB.pdf>Acesso em: 04.maio 2008.

REDE SACI : Solidariedade, Apoio, Comunicação e Informação Disponível em: http://saci.org.br/ Acesso em: 22 set. 2005.

ROCHA, Heloísa Vieira da, BARANAUSKAS, Maria Cecília Calani. Design e Avaliação de Interfaces Humano-Computador. Campinas: NIED/ UNICAMP, 2003. Disponível em: < http://www.nied.unicamp.br/ publicacoes $/$ pub.php?classe $=$ livro\&cod_publicacao $=73>$ Acesso em 02 de maio de 2008.

SASSAKI, Romeu Kazumi. Inclusão: construindo uma sociedade para todos. 3.ed. Rio de Janeiro: WVA, 1999.

SILVA, O. M. da. A epopéia ignorada: a pessoa deficiente na história do mundo de ontem e de hoje. São Paulo: Ed. Cedas, 1986. 